\title{
THE DIFFERENTIATION OF VISUAL SENSORIMOTOR PROCESSES IN THE REPRESENTATIVES OF VARIOUS SPORT DISCIPLINES
}

\author{
Piotr Lesiakowski, ${ }^{1, A, B, C, ~ D, ~ E ~ J u s t y n a ~ K r z e p o t a, ~}{ }^{2, B}$ Teresa Zwierko², A, D, E \\ ${ }^{1}$ Pomeranian Medical University in Szczecin, Department of Physical Education and Sport, Szczecin, Poland \\ 2 University of Szczecin, Faculty of Physical Culture and Health Promotion, Szczecin, Poland

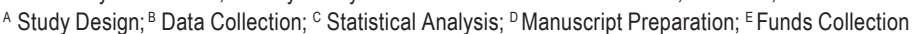

\author{
Address for corpespondence: \\ Piotr Lesiakowski \\ Pomeranian Medical University in Szczecin, Department of Physical Education and Sport \\ Dunikowskiego 6a, 70-123 Szczecin, Poland \\ E-mail: lesiakowskipiotr@gmail.com
}

\begin{abstract}
Ahstract Sport activities usually require a high efficiency of visual information processing. Therefore, it seems justified to determine the efficiency of visual sensorimotor processes in sports requiring a variety of perception competencies. The aim of this study was to assess the differentiation of sensorimotor processes in terms of simple and choice reaction time, and visual stimulus discrimination in various athletes and untrained persons. The study involved 119 men, of which 95 were athletes: football players $(n=24)$, volleyball players $(n=22)$, boxers $(n=26)$, and rowers $(n=23)$. The efficiency of sensorimotor processes was evaluated with the Vienna Test System (Schuhfried, Austria). The evaluations included simple reaction time (SRT), choice reaction time (CRT), and visual stimulus discrimination. Analysis of the results showed that volleyball and football players had shorter $(p<0.01)$ reaction times compared to non-athletes and representatives of the other sports. We found significant differences $(p<0.01)$ between athletes and non-athletes in visual stimulus discrimination. In addition, boxers showed fewer correct reactions than volleyball players, and shorter times of stimulus detection than in volleyball and soccer players.
\end{abstract}

Key Worls reaction time, selective attention, sport training

\section{Introduction}

It is widely accepted that regular physical activity positively affects the efficiency of motor reactions. For example, Baylor and Spirduso (1988) found that regular physical activity improves the efficiency of simple reaction times, more with regards to the pre-motor fraction (70\%) than to motor fraction of the reaction time (30\%). Many researchers confirm this thesis, reporting faster response times in athletes in comparison with non-athletes (Ando, Kida, Oda, 2001; Kioumourtzoglou, Kourtessis, Michalopoulou, Derri, 1998; Kokubu, Ando, Kida, Oda, 2006; Overney, Blanke, Herzog, 2008; Piras, Lobietti, Squatrito, 2014; Vansteenkiste, Vaeyens, Zeuwts, Philippaerts, Lenoir, 2014; Zwierko, Osiński, Lubiński, Czepita, Florkiewicz, 2010). On the other hand, not all articles confirm the existence of a relationship between the efficiency of motor reactions and physical fitness (Cojocarlu and Abalasel 
2014; Fontani, Lodi, Felici, Migliorini, Corradeschi, 2006; Soto-Rey, Pérez-Tejero, Rojo-González, Reina, 2014). Importantly, most research in this field refers to laboratory measurements of reactions in athletes and non-athletes, and a lack of difference is observed more frequently in less complex tasks (Kida, Oda, Matsumura, 2005; Mero, Jaakkola, Komi, 1989; Thomson, Watt, Liukkonen, 2008).

Attention is considered to be an important factor influencing the effectiveness of motor performance in sport, and hence the athletes' tolerance to fatigue (Williams, Davids, Williams, 1999). It is generally defined as the state of readiness (vigilance) of the body to detect specific stimuli. Various reports show that a higher level of attention increases the perceptual sensitivity of athletes, as manifested by an increased efficiency of visual search and specific decision-making processes, as well as by a shorter time of information processing (Cañal-Bruland, 2009; Hagemann, Schorer, Cañal-Bruland, Lotz, Strauss, 2010; Lu, Dosher, 1998; Taliep et al. 2008). For example, football, handball and hockey players, as well as modern pentathletes, have been observed to have a higher level of attention than non-athletes (Enns, Richards, 1997; Lum, Enns, Pratt, 2002; Nougier, Ripoll, Stein, 1989; Zwierko, Florkiewicz, Fogtman, Kszak-Krzyżanowska, 2014).

The specificity of each discipline requires performing different physical activities under established rules. However, there is a scarcity of research comparing the effectiveness of sensorimotor processes in disciplines with a wide spectrum of perceptual requirements. Existing research suggests differences in the level of visual sensorimotor processes between sports with varied requirements regarding perception. For example Giglia et al. (2011) compared the effectiveness of perceptual processes in volleyball and rowing, and found a significantly faster response and greater accuracy in volleyball players. The dependence of reaction time and attention on the type of sporting activity is partly explained by other experimental studies (Foroghipour, Monfared, Pirmohammadi, Saboonchi, 2013; Hijazi, 2013; Matser, Kessels, Lezak, Troost, Jordan, 2000; Mokha, Kaur, Sidhu, 1992; SánchezLópez, Fernández, Silva-Pereyra, 2008; Warden et al. 2001).

Given the aforementioned assumptions, it seems important to determine the scope of adaptation of visual functions to conditions associated with the nature and duration of sports training. The aim of this study was to evaluate differences in sensorimotor processes in terms of simple and choice reaction time, and visual stimulus discrimination, in athletes training in sports requiring different levels of perceptual involvement compared to nonathletes. We hypothesized that the efficiency of visual sensorimotor processes depends on the kind of sports activity taken up, that means that the higher the level of requirements for the engaged visual functions resulting from the specificity of motor behavior in a given sports discipline, the higher the efficiency of visual sensorimotor processes.

\section{Material and methods}

The study involved 119 men. Of those, 95 were professionally involved in sport: football $(n=24)$, volleyball ( $n=22)$, boxing $(n=26)$, rowing $(n=23)$. The control group consisted of non-athletes $(n=24)$. Table 1 shows the main characteristics of the study groups.

To evaluate the effectiveness of sensorimotor processes we applied measurement methods included in the Vienna Test System, version 29.01 (Schuhfried, Austria). The study used a computer (CPU 1.6GHz) and a screen (Dell P791, diagonal 17", resolution $640 \times 480$ pixels, refresh rate $85 \mathrm{~Hz}$ ). The study evaluated the simple reaction time (SRT), choice reaction time (CRT) and ability to maintain attention during visual stimulus discrimination. 
Table 1. Somatic parameters and length of training groups studied $(\bar{x} \pm S D)$

\begin{tabular}{lcccc}
\hline \multicolumn{1}{c}{ Group } & $\begin{array}{c}\text { Age } \\
\text { (years) }\end{array}$ & $\begin{array}{c}\text { Body height } \\
(\mathrm{cm})\end{array}$ & $\begin{array}{c}\text { Body mass } \\
(\mathrm{kg})\end{array}$ & Sport experience (years) \\
\hline Football & $20.25 \pm 1.91$ & $181.04 \pm 7.29$ & $73.93 \pm 7.39$ & $6.54 \pm 2.96$ \\
Volleyball & $21.92 \pm 2.11$ & $194.06 \pm 6.22$ & $84.92 \pm 7.04$ & $8.14 \pm 1.31$ \\
Boxing & $20.16 \pm 1.84$ & $173.41 \pm 5.16$ & $61.51 \pm 6.05$ & $6.03 \pm 3.22$ \\
Rowing & $21.83 \pm 1.86$ & $185.89 \pm 5.81$ & $82.36 \pm 12.41$ & $6.82 \pm 3.48$ \\
Non-athletes & $20.14 \pm 1.42$ & $182.04 \pm 3.95$ & $80.23 \pm 7.21$ & - \\
\hline
\end{tabular}

Simple reaction time (SRT) was evaluated using the reaction test $(\mathrm{T})$ - variant $\mathrm{S} 1$. The reaction cycle consisted of 28 yellow light stimuli generated at different and randomly selected time intervals (2.5-6.0 s). Each stimulus lasted 1 second. The participants were supposed to perform a key-press response to the programmed visual stimuli. Below the 'reaction key', the panel had a 'stand-by key'. An examined individual maintained a finger on the 'stand-by key'; in reaction to a visual stimulation, the finger was supposed to be moved as quickly as possible from the 'stand-by key' to the 'reaction key'.

Choice reaction time (CRT) was assessed using the reaction test (T) - variant S4. Similarly, to test the response time of a simple choice, the person tested sat in front of the screen. Presentation of complex visual stimuli consisted of 48 stimuli with different characteristics (light yellow and/or red with a sound signal frequency $2000 \mathrm{~Hz}$ ). The length of the emitted stimulus was 1.2 seconds, and the interval between stimuli was varied in the range 1.5 to 4.0 seconds. The test duration was five minutes.

Choice reaction time (variant S4). In the test phase 48 stimuli were presented of which 16 required a reaction. The critical combination to which the subject was instructed to respond consisted of two visual stimuli (yellow and/or red light with a sound signal at $2000 \mathrm{~Hz}$ ). An examined individual was supposed to react to the programmed visual stimuli (simultaneous yellow and red lights) by pressing the 'reaction key' according to the procedure mentioned above (SRT). The measurements of SRT and CRT were recorded by a computer program and the following values were calculated: (1) median of total reaction time (duration between the beginning of a given stimulus and pressing the 'reaction key', in ms), (2) median of pre-motor reaction time (duration between the beginning of a given stimulus and the release of the 'stand-by' key, in ms), (3) median of motor reaction time (duration between the release of the 'stand-by' key and pressing the 'reaction key', in ms).

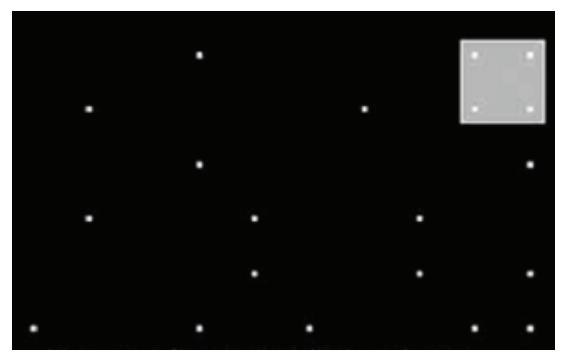

Figure. 1. White signals (dots) on a black background and the critical stimulus constellation in the Special Ability Signal Test 
The ability to maintain attention during the discrimination of visual stimuli (long-term selective attention) was assessed using the standard variant of the Special Ability Signal Test (S1). The test measured the visuospatial differentiation of a relevant signal within irrelevant signals. In our experiment we used the standard version S1 with white signals (dots) on a black background. Dots were displayed over the entire screen area; pseudo-randomly some of the dots disappeared and others appeared. The participants were requested to perform a key-press response to a programmed stimulus constellation whenever it occurred. This critical stimulus constellation consisted of four dots forming a square (Figure 1). The total testing time was between 13 and 14 minutes (including instruction and practice phase). The main variables calculated were the numbers of correct, omitted and incorrect reactions and the median reaction time as a measure of the speed of the detection process.

\section{Results}

Table 2. Arithmetic means, standard deviations, minimum and maximum values, and variance analysis of simple reaction time [s] and choice reaction time $[\mathrm{s}]$ in the examined groups

\begin{tabular}{lcccccc}
\hline \multirow{2}{*}{ Group } & \multicolumn{3}{c}{ Simple reaction time } & \multicolumn{3}{c}{ Choice reaction time } \\
\cline { 2 - 7 } & $\overline{\mathrm{x}} \pm \mathrm{SD}$ & Minimum & Maximum & $\overline{\mathrm{x}} \pm \mathrm{SD}$ & Minimum & Maximum \\
\hline Football & $0.255 \pm 0.018$ & 0.221 & 0.275 & $0.365 \pm 0.028$ & 0.318 & 0.406 \\
Box & $0.307 \pm 0.039$ & 0.236 & 0.393 & $0.428 \pm 0.030$ & 0.366 & 0.496 \\
Rowing & $0.296 \pm 0.036$ & 0.231 & 0.389 & $0.440 \pm 0.045$ & 0.351 & 0.530 \\
Volleyball & $0.253 \pm 0.024$ & 0.221 & 0.299 & $0.365 \pm 0.028$ & 0.318 & 0.406 \\
Non-athletes & $0.289 \pm 0.037$ & 0.239 & 0.387 & $0.403 \pm 0.061$ & 0.282 & 0.507 \\
\hline
\end{tabular}

Table 2 shows the descriptive statistics and the variance analysis of simple reaction time (SRT) and choice reaction time (CRT) in the examined groups. The shortest combined SRT and CRT were obtained by volleyball and football players. Detailed comparative analysis (Table 3$)$ indicated their significantly shorter SRT $(p<0.01)$ in relation to the results achieved by boxers, rowers and the control group. Also in CRT (Table 4), football and volleyball players had significantly better results $(p<0.01)$ than rowers and boxers. In two out of four analyzed cases (soccer, volleyball), the sport groups had better CRT than the control group $(p<0.05)$.

Table 3. The results of the Tukey post-hoc test for simple reaction time [s] in the study groups

\begin{tabular}{llllll}
\hline \multicolumn{1}{c}{ Group } & $\{1\}$ & $\{2\}$ & $\{3\}$ & $\{4\}$ & $\{5\}$ \\
\hline Soccer $\{1\}$ & - & $* *$ & $* *$ & ns & $* *$ \\
Boxing $\{2\}$ & $* *$ & - & ns & $* *$ & ns \\
Rowing $\{3\}$ & $* *$ & ns & - & $* *$ & ns \\
Volleyball $\{4\}$ & ns & $* *$ & $* *$ & - & $* *$ \\
Non-athletes $\{5\}$ & $* *$ & ns & ns & $* *$ & - \\
\hline
\end{tabular}

${ }^{* *} p<0.01 ; n s-$ not significant. 
Tahle 4. The results of the Tukey post-hoc test for choice reaction times [s] in the studied groups

\begin{tabular}{lccccc}
\hline \multicolumn{1}{c}{ Group } & $\{1\}$ & $\{2\}$ & $\{3\}$ & $\{4\}$ & $\{5\}$ \\
\hline Soccer $\{1\}$ & - & $* *$ & $* *$ & ns & $*$ \\
Boxing $\{2\}$ & $* *$ & - & ns & $* *$ & ns \\
Rowing $\{3\}$ & $* *$ & ns & - & $* *$ & $*$ \\
Volleyball $\{4\}$ & ns & $* *$ & $* *$ & - & $*$ \\
Non-athletes $\{5\}$ & $*$ & ns & $*$ & $*$ & - \\
\hline
\end{tabular}

${ }^{*} p<0.05 ;{ }^{* *} p<0.01 ; n s-$ not significant.

We observed statistically significant differences in selective attention expressed by correct responses $\left(\mathrm{F}_{(4,111)}\right.$ $=7.865 ; p<0.05)$ and the time of stimulus $\left(F_{(4,111)}=4.645 ; p<0.05\right)$. In the case of incorrect responses, we found no significant differences between the groups (Table 5 ).

Table 5. Arithmetic means, standard deviations and variance analysis of selective attention during visual stimulus discrimination

\begin{tabular}{|c|c|c|c|c|c|c|}
\hline \multirow{2}{*}{ Group } & \multicolumn{2}{|c|}{ Correct responses } & \multicolumn{2}{|c|}{ Incorrect responses } & \multicolumn{2}{|c|}{ Detection time [s] } \\
\hline & $\bar{x} \pm S D$ & $\mathrm{~F}$ & $\bar{x} \pm S D$ & $\mathrm{~F}$ & $\bar{x} \pm S D$ & $\mathrm{~F}$ \\
\hline Football & $53.208 \pm 2.903$ & \multirow{5}{*}{$7.865^{*}$} & $1.083 \pm 0.775$ & \multirow{5}{*}{1.278} & $0.760 \pm 0.050$ & \multirow{5}{*}{$4.645^{*}$} \\
\hline Boxing & $50.612 \pm 4.104$ & & $1.903 \pm 2.150$ & & $0.830 \pm 0.082$ & \\
\hline Rowing & $52.947 \pm 4.870$ & & $1.631 \pm 1.256$ & & $0.783 \pm 0.076$ & \\
\hline Volleyball & $54.047 \pm 3.721$ & & $1.904 \pm 1.410$ & & $0.766 \pm 0.059$ & \\
\hline Non-athletes & $48.619 \pm 2.558$ & & $1.574 \pm 1.028$ & & $0.798 \pm 0.060$ & \\
\hline
\end{tabular}

${ }^{*} p<0.05$.

Analysis of differences between groups in correct reactions and stimulus detection time are shown in Tables 6 and 7.

Table 6. Results of the Tukey post-hoc test for correct reactions in the visual stimulus discrimination

\begin{tabular}{lccccc}
\hline \multicolumn{1}{c}{ Group } & $\{1\}$ & $\{2\}$ & $\{3\}$ & $\{4\}$ & $\{5\}$ \\
\hline Soccer $\{1\}$ & - & ns & ns & ns & $* *$ \\
Boxing $\{2\}$ & ns & - & ns & $*$ & ns \\
Rowing $\{3\}$ & ns & ns & - & ns & $* *$ \\
Volleyball $\{4\}$ & ns & $*$ & ns & - & $* *$ \\
Non-athletes $\{5\}$ & $* *$ & ns & $* *$ & $* *$ & - \\
\hline
\end{tabular}

${ }^{*} p<0.05 ;{ }^{* *} p<0.01 ; n s-$ not significant.

Detailed analysis of results of the researched groups of athletes showed the groups of athletes, volleyball players characterized more $(p<0.05)$ correct responses compared to those boxing. Moreover, the reaction was significantly better $(p<0.01)$ in the groups of volleyball players, football players, rowers, when compared with the non-athletes. 
Table 7. The results of the Tukey post-hoc test for the detection time [s] of visual stimulus discrimination in groups

\begin{tabular}{llllll}
\hline \multicolumn{1}{c}{ Group } & $\{1\}$ & $\{2\}$ & $\{3\}$ & $\{4\}$ & $\{5\}$ \\
\hline Football $\{1\}$ & - & $* *$ & ns & ns & ns \\
Boxing $\{2\}$ & $* *$ & - & ns & $*$ & ns \\
Rowing $\{3\}$ & ns & ns & - & ns & ns \\
Volleyball $\{4\}$ & ns & $*$ & ns & - & ns \\
Non-athletes $\{5\}$ & ns & ns & ns & ns & - \\
\hline
\end{tabular}

${ }^{*} p<0.05 ;{ }^{* *} p<0.01 ; n s-$ not significant.

The selection of a correct sequence of stimuli on the computer screen was fastest for football players, and then volleyball players. The results obtained by these groups of athletes were significantly better $(p<0.01$ and $p<0.05$ ) compared to the results achieved by the boxers (Table 8 ). In other cases we found no significant differences between groups ( $p>0.05)$.

\section{Discussion}

The aim of this study was to evaluate differences in visual sensorimotor processes in terms of simple and choice reaction time, and visual stimulus discrimination in the representatives of various sport disciplines. We expected that the higher the level of requirements for the engaged visual functions resulting from the specificity of motor behavior in a given sports discipline, the higher the efficiency of visual sensorimotor processes. This hypothesis was partly confirmed. Our results partially indicate a shorter reaction time $(p<0.01)$ in athletes compared with nonathletes, albeit only in the groups of footballers and volleyball players. This confirms earlier reports by Ando et al. (2001) who determined changes in the bioelectrical charge in the forearm muscles to assess the reaction to stimuli appearing in the central and peripheral vision in highly-skilled footballers. The specificity of football requires a state of readiness to respond to stimuli that may arise in the field of view. When it comes to volleyball players, our results are in line with the observations of Piras et al. (2014) and Vansteenkiste et al. (2014) who evaluated the reaction time based on the video of registered sequences of volleyball actions. Also, studies of other authors (Kokubu et al. 2006; Kioumourtzoglou et al. 1998; Zwierko et al. 2010) confirmed shorter reaction times straight in volleyball players compared to non-athletes.

Interestingly, we found no significant differences in simple and choice reaction times between boxers and non-athletes. The control group had an even shorter mean simple reaction time, although the difference was not statistically significant $(p>0.05)$. It seems that the nature and specificity of boxing requires a high level of rapid response capabilities, as documented in the works of Darby et al. (2014) and Bianco et al. (2011), etc. However, the results of our study do not confirm it. Some explanation of this discrepancy may be provided by the traumatic effect of boxing, especially regarding head injuries (Zazryn, Finch, McCrory, 2003). A common phenomenon in combat sport is a long-term presence of symptoms indicative of previous head injuries (Galetta et al. 2011). For example, McKee et al. (2009) presented detailed results of football players and boxers, confirming the long-term effects of repeated head injuries, resulting in progressive neurological deterioration known as chronic traumatic encephalopathy (CTE). Some results of research conducted among athletes also indicate the possible influence of frequent blows to the head on the speed of sensorimotor processing speed and the efficiency of cognitive 
functions. They mainly related to football players (Koerte, Ertl-Wagner, Reiser, Zafonte, Shenton, 2012; Matser et al. 2001), hockey players (McAllister et al. 2012) and boxers (Chappell et al. 2006; Jordan et al. 1997; Zhang, Heier, Zimmerman, Jordan, Ulug, 2006).

In this study, rowers had slower reactions $(p<0.05)$ than non-athletes. Of course, given the specificity of the sport, it can be predicted that this group of athletes may not be different from untrained persons. Previous research on rowers showed that the choice reaction time was clearly longer than volleyball players (Giglia et al. 2011). It is assumed, therefore, that in the absence of additional effects which would modulate the reactivity to stimuli (forced by the specificity of the discipline), reactivity is strongly influenced by stimuli not related to sports.

When it comes to selective attention during visual stimulus discrimination, most analyzed sports showed significant differences between the athletes and non-athletes in the number of correct responses in stimulus discrimination. No differences were found in the time of discrimination.

It seems that sporting experience should result in faster and more efficient information processing associated with attention (Borysiuk, Sadowski, 2007; Di Russo, Taddei, Aprile, Spinelli, 2006). An optimal level is considered significant for the efficiency of visual search as well as the time needed to process the information (Cañal-Bruland, 2009; Hagemann et al. 2010). Our results confirm only an increase in the efficiency of information processing manifested by a greater number of correct answers from athletes, which is consistent with the results of other authors. In previous studies we observed a higher level of attention in athletes involved in sports such as football, handball, hockey and modern pentathlon, when compared to untrained persons (Enns, Richards, 1997; Lum et al. 2002; Nougier et al. 1989; Pesce, Tessitore, Casella, Pirritano, Capranica, 2007; Zwierko et al. 2014).

Therefore, it is possible that sport training facilitates a wider range of adaptation and enhances selective attention during stimulus discrimination, particularly in the case of sports requiring a strong involvement in visual perception. Specific explanations may be provided here by a list of sports arranged according to the involvement of visual perceptual functions.

In our study, the selection of disciplines was based on the classification proposed by Williams et al. (1999) and Erickson (2007), where the highest requirements in terms of perception are found in football, followed by volleyball and boxing, and the least demanding in terms of visual perception is rowing. Our results were similar, with the shortest reaction times observed in football and volleyball players, with significantly better $(p<0.01)$ results than representatives of other sports. Our findings seem to be consistent with previous research by other authors. Giglia et al. (2011) compared the effectiveness of perceptual processes in volleyball players and rowers, and clearly showed a faster reaction and greater accuracy in volleyball players, especially with regard to peripherally appearing stimuli. The dependence of the reaction time to the type of sport activity is explained in other experimental studies. For example, Foroghipour et al. (2013) subjected two groups of people to a systematic sport activity. One group trained table tennis while the other trained volleyball (24 training sessions each). The group training table tennis had significantly reduced simple and choice reaction time when compared to the test before the training sessions $(p<0.05)$, while in the volleyball group a reduction in just the choice reaction time was observed $(p<0.05)$. Similar results were obtained by Mokha et al. (1992), who evaluated the reaction time after 20 days of intensive hockey training. It turned out that the speed of reaction to visual stimuli significantly improved in defenders and attackers. As can be seen, our results and previous reports confirm the assumption that the engagement of perceptual functions in a sport is a factor determining the reaction time. Probably, one of the factors that is crucial for the efficiency of sensorimotor processes is the ability to quickly focus attention during body movement. 
Our results, concerning selective attention during visual stimulus discrimination, showed differences between the sports. Volleyball and football players needed less time to detect a stimulus compared to boxers. In addition, volleyball players obtained a greater number of correct answers than boxers. Therefore, our research shows that athletes training sports with high requirements regarding visual perception achieve better results in long-term attention tests. However, the results of previous studies do not clearly confirm this, showing slightly different dependencies. In an analysis of three primary (non-specific) tasks independently determining the level of attention in handball players and athletes of individual sports, Memmert et al. (2009) did not register any significant difference in the efficiency of processes related to attention. In this case, the discrepancy with our results may be due to the cross-sectional selection of the study groups, which included several individual sports differing in perceptual requirements and so in the levels of attention.

A direct comparison between the level of attention between combat athletes representing three martial arts was performed by Sánchez-López et al. (2013). These included kung-fu, judo and taekwondo, seemingly similar in terms of the involvement of sensorimotor processes. Based on the TOVA test results, the authors found a shorter time of stimulus detection $(p<0.05)$ and more effective attention in kung-fu athletes, which was manifested by a higher level of refraining from reacting to disturbing stimuli than the other groups. The authors associated these observations with more time spent on meditation or self-control in kung-fu athletes, which seems to confirm the results of our study indicating that attention depends on the type of activities performed in individual sports. In yet another study, Khani et al. (2012), analyzed selected attention parameters: accuracy, impulsiveness, and speed of information processing, in boxers with different sport experience and sprinters at the beginner level. The authors did not observe any significant differences in the attention between the two groups. Given the results of our research, it is therefore possible that the lower level of attention observed in boxers when compared to the representatives of team sports, may result from the effects of trauma they experienced during fights. Previous studies show the negative effects of combat sports on cognitive functions such as planning and attention (Matser et al. 2000; Warden et al. 2001). Yet, as can be seen in literature, results regarding attention in boxing are ambiguous.

In the case of football or volleyball, i.e. disciplines with a high level of perceptual requirement, long-term attention is a consequence of the specific nature of the motor activities. There are scientific studies confirming the association between observations of motor activities and the mechanisms of attention in sports with high perceptual requirements. For example, Taliep et al. (2008) when analyzing the efficiency of attention processes in cricket players, observed a lower amplitude of the P300 wave (recognized as a psychophysiological measure of attention processes), faster reaction time and better discrimination and recognition of correct stimuli (film presentation of different kinds of ball throws). The authors suggested that players training sport with high perceptual requirements engaged less attention during recognition of the type of throw than other persons. This shows the significance of perceptual training in improving attention in sports. The use of software in improving perception functions brings positive results in the form of an increased level of attention, which directly increases the effectiveness of motor learning and consequently improves sport performance (Cañal-Bruland, 2009; Hagemann et al. 2010; Uehara, Button, Davids, 2008; Wulf, McConnel, Gärtner, Schwarz, 2002).

With reference to the direct usefulness in the process of sports practice, the visual attention exercises should be treated as a necessary element of sports training, especially in the disciplines characterized by high requirements connected to visual perception. 


\section{References}

Ando, S., Kida, N., Oda, S. (2001). Central and peripheral visual reaction time of soccer players and nonathletes. Perceptual and Motor Skills, 92 (3), 786-794.

Baylor, A.M., Spirduso, W.W. (1988). Systematic aerobik exercise and components of reaction time in older women. Journal of Gerontology and Psychological Sciences, 43, 121-126.

Bianco, M., Ferri, M., Fabiano, C., Giorgiano, F., Tavella, S., Manili, U., Faina, M., Palmieri, V., Zeppilli, P. (2011). Baseline simple and complex reaction times in female compared to male boxers. Journal of Sports Medicine and Physical Fitness, 51 (2), $292-298$.

Borysiuk, Z., Sadowski, J. (2007). Time and spatial aspects of movement anticipation. Biology of Sport, 3, 285-295.

Cañal-Bruland, R. (2009). Visual cueing in sport-specific decision making International. Journal of Sport and Exercise Psychology, 7 (4), 450-464.

Chappell, M.H., Ulug, A.M., Zhang, L., Heitger, M.H., Jordan, B.D., Zimmerman, R.D., Watts, R. (2006). Distribution of microstructural damage in the brains of professional boxers: A diffusion MRI study. Journal of Magnetic Resonance Imaging, 24 (3), $537-542$.

Cojocarlu, A., Abalasel, B. (2014). Does the reaction time to visual stimuli contribute to performance in judo? Archives of Budo, 10 , 73-78.

Darby, D., Moriarity, J., Pietrzak, R., Kutcher, J., McAward, K., McCrory, P. (2014). Prediction of winning amateur boxers using pretournament reaction times. Journal of Sports Medicine and Physical Fitness, 54 (3), 340-346.

Di Russo, F., Taddei, F., Aprile, T., Spinelli, D. (2006). Neural correlates of fast stimulus discrimination and response selection in top level fencers. Neuroscience Letters, 408, 113-118.

Enns, J.T., Richards, J. (1997). Visual attentional orienting in developing hockey players. Journal of Experimental Child Psychology, $64,255-275$.

Erickson, G. (2007). Sports Vision: Vision Care for the Enhancement of Sports Performance. St. Louis: Butterworth-Heinemann.

Fontani, G., Lodi, L., Felici, A., Migliorini, S., Corradeschi, F. (2006). Attention in athletes of high and low experience engaged in defferent open skill sports. Perceptual and Motor Skills, 102 (3), 791-805.

Foroghipour, H., Monfared, M.O., Pirmohammadi, M., Saboonchi, R. (2013). Comparison of Simple and Choice Reaction Time in Tennis and Volleyball Players. International Journal of Sport Studies, 3 (1), 74-79.

Galetta, K.M., Barrett, J., Allen, M., Madda, F., Delicata, D., Tennant, A.T., Branas, C.C., Maguire, M.G., Messner, L.V., Devick, S., Galetta, S.L., Balcer, L.J. (2011). The King-Devick test as a determinant of head trauma and concussion in boxers and MMA figters. Neurology, 76 (17), 1456-1462.

Giglia, G., Brighina, F., Zangla, D., Bianco, A., Chiavetta, E., Palma, A., Fierro, B. (2011). Visuospatial attention lateralization in volleyball players and in rowers. Perceptual and Motor Skills, 112 (3), 915-925.

Hagemann, N., Schorer, J., Cañal-Bruland, R., Lotz, S., Strauss, B. (2010). Visual perception in fencing: do the eye movements of fencers represent their information pickup? Attention, Perception and Psychophysics, 72 (8), 2204-2214.

Hijazi, M. (2013). Attention, Visual Perception and their Relationship to Sport Performance in fencing. Journal of Human Kinetics, 39, 195-201.

Jordan, B.D., Relkin, N.R., Ravdin, L.D., Jacobs, A.R., Bennett, A., Gandy, S. (1997). Apolipoprotein E epsilon4 associated with chronic traumatic brain injury in boxing. Journal of the American Medical Association, 278 (2), 136-140.

Khani, M., Farrokhi, A., Kheslat, S.D.N., Sadri, K., Farrar, A. (2012). Chronic attention impairments in amateur boxing: Effect of repeated blows to the head. Serbian Journal of Sports Sciences, 6 (1), 23-28.

Kida, N., Oda, S., Matsumura, M. (2005). Intensive baseball practice improves the Go/NoGo reaction time, but not the simple reaction time. Cognitive Brain Research, 22 (2), 257-264.

Kioumourtzoglou, E., Kourtessis, T., Michalopoulou, M., Derri, V. (1998). Differences in several perceptual abilities between experts and novices in basketball, volleyball and water-polo. Perceptual and Motor Skills, 86 (3), 899-912.

Koerte, I.K., Ertl-Wagner, B., Reiser, M., Zafonte, R., Shenton, M.E. (2012). White matter integrity in the brains of professional soccer players without a symptomatic concussion. Journal of the American Medical Association, 308 (18), 1859-1861.

Kokubu, M., Ando, S., Kida, N., Oda, S. (2006). Interference effects between saccadic and key press reaction times of volleyball players and nonathletes. Perceptual and Motor Skills, 103 (3), 709-716.

Lu, Z.L., Dosher, B.A. (1998). External noise distinguishes attention mechanisms. Vision Research, 38, 1183-1198. 
Lum, J., Enns, J.T., Pratt, J. (2002). Visual orienting in the college athletes: Explorations of athlete type and gender. Research Quarterly for Exercise and Sport, 73, 156-167.

Matser, E.J., Kessels, A.G., Lezak, M.D., Troost, J., Jordan, B.D. (2000). Acute traumatic brain injury in amateur boxing. The Physician and Sportsmedicine, 28 (1), 87-92.

Matser, J.T., Kessels, A.G., Lezak, M.D., Troost, J. (2001). A dose-response relation of headers and concussions with cognitivie impairment in professional soccer players. Journal of Clinical and Experimental Neuropsychology, 23 (6), 770-774.

McAllister, T.W., Flashman, L.A., Maerlender, A., Greenwald, R.M., Beckwith, J.G., Tosteson, T.D., Crisco, J.J., Brolinson, P.G., Duma, S.M., Duhaime, A.C., Grove, M.R., Turco, J.H. (2012). Cognitive effects of one season of head impacts in a cohort of collegiate contact sport athletes. Neurology, 78 (22), 1777-1784.

McKee, A.C., Cantu, R.C., Nowinski, C.J., Hedley-Whyte, E.T., Gavett, B.E., Budson, A.E., Santini, V.E., Lee, H.S., Kubilus, C.A., Stern, R.A. (2009). Chronic traumatic encephalopathy in athletes: Progressive tauopathy after repetitive head injury. Journal of Neuropathology and Experimental Neurology, 68 (7), 709-735.

Memmert, D., Simons, D.J., Grimme, T. (2009). The relationship between visual attentionand expertise in sports. Psychology of Sport Exercise, 10 (1), 146-151.

Mero, A., Jaakkola, L., Komi, P.V. (1989). Neuromuscular, metabolit and hormonal profile sof young tennis players and untrained boys. Journal of Sport Sciences, 7 (2), 95.

Mokha, R., Kaur, G., Sidhu, L.S. (1992). Effect of training on the reaction time of Indian female hockey players. Journal of Sports Medicine and Physical Fitness, 32 (4), 428-431.

Nougier, V., Ripoll, H., Stein, J.F. (1989). Orienting of attention with highly skilled athletes. International Journal of Sport Psychology, 20, 205-223.

Overney, L.S., Blanke, O., Herzog, M.H. (2008). Enhanced temporal but not attentional processing in expert tennis players. PLoS ONE, $3(6), 1-9$.

Pesce, C., Tessitore, A., Casella, R., Pirritano, M., Capranica, L. (2007). Focusing of visual attention at rest and during physical exercise in soccer players. Journal of Sports Science, 25 (11), 1259-1270.

Piras, A., Lobietti, R., Squatrito, S. (2014). Response Time, Visual Search Strategy and Anticipatory Skills in Volleyball Players. Journal of Ophthalmology. DOI: 10.1155/2014/189268.

Sánchez-López, J., Fernández, T., Silva-Pereyra, J. (2013). Differences between Judo, Taekwondo and Kung-fu Athletes in Sustained Attention and Impulse Control. Psychology, 4 (7), 607-612.

Soto-Rey, J., Pérez-Tejero, J., Rojo-González, J.J., Reina, R. (2014). Study of reaction time to visual stimuli in athletes with and without a hearing impairment. Perceptual and Motor Skills, 119 (1), 123-132.

Taliep, S.M., St Clair, G.A., Gray, J., Van der Merwe, L., Vaughan, C.L., Noakes, T.D., Kellaway, L.A., John, L.R. (2008). Event-related potentials, reaction time, and response selection of skilled and less-skilled cricket batsmen. Perception, 37, 96-105.

Thomson, K., Watt, A., Liukkonen, J. (2008). Skill-related differences between athletes and nonathletes in speed discrimination. Perceptual and Motor Skills, 107, 893-900.

Uehara, L.A., Button, C., Davids, K. (2008). The effects of focus of attention instructions on novices learning soccer chip. Brazilian Journal of Biomotricity, 63-77.

Vansteenkiste, P., Vaeyens, R., Zeuwts, L., Philippaerts, R., Lenoir, M. (2014). Cue usage in volleyball: a time course comparison of elite, intermediate and novice female players. Biology of Sport, 31 (4), 295-302.

Warden, D.L., Bleiberg, J., Cameron, K.L., Ecklund, J., Walter, J., Sparling, M.B., Reeves, D., Reynolds, K.Y., Arciero, R. (2001). Persistent prolongation of simple reaction time in sports concussion. Neurology, 57, 524-526.

Williams, A.M., Davids, K., Williams, J.G. (1999). Visual perception and action in sport. London: Taylor \& Francis.

Wulf, G., McConnel, N., Gärtner, M., Schwarz, A. (2002). Enhancing the Learning of Sport Skills Through External-Focus Feedback. Journal of Motor Behavior, 34 (2), 171-182.

Zazryn, T.R., Finch, C.F., McCrory, P. (2003). A 16 year study of injuries to professional boxers in the state of Victoria, Australia. Britain Journal of Sports Medicine, 37, 321-324.

Zhang, L., Heier, L.A., Zimmerman, R.D., Jordan, B., Ulug, A.M. (2006). Diffusion anisotropy changes in the brains of professional boxers. American Journal of Neuroradiology, 27 (9), 2000-2004. 
Zwierko, T., Osiński, W., Lubiński, W., Czepita, D., Florkiewicz, B. (2010). Speed of Visual Sensorimotor Processes Conductivity of Visual Pathway in Volleyball Players. Journal of Human Kinetics, 23, 21-27.

Zwierko, T., Florkiewicz, B., Fogtman, S., Kszak-Krzyżanowska, A. (2014). The ability to maintain attention during visuomotor task performance in handball players and non-athletes. Central European Journal of Sport Sciences and Medicine, 7 (3), 99-106.

Cite this article aS: Lesiakowski, P., Krzepota, J., Zwierko, T. (2017). The Differentiation of Visual Sensorimotor Processes in the Representatives of Various Sport Disciplines. Central European Journal of Sport Sciences and Medicine, 19 (3), 43-53. DOI: 10.18276/cej.2017.3-04. 
